\title{
Insights Into the Tensions Facing Western Christians Working Overseas in an Educational Faith-Based Organization - A Case Study
}

\section{Introduction}

Education has received a key role as a development strategy for eradicating poverty after traditional strategies such as economic growth have proven to be insufficient (Tarabini, 2010). Major summits such as Education for All in Jomtien in 1990 and in Dakar in 2000, and the implementation of the Millennium Development Goals in 2000 and the Sustainable Development Goals in 2016 have significantly contributed to solidify this strategy. All the major development institutions have adopted it. The World Bank has emerged as a major player in the now globalized education field. It publishes influential research reports and strategy papers that lay the foundation for the international educational agenda, such as Voices of the Poor (Narayan et al., 2000) or the Education Strategy 2020 (World Bank, 2011). Education is a human right and there is a broad consensus between governments, international organizations and NGOs that investment in education is beneficial for national and personal development. However, critical voices have been raised about the way in which this educational agenda is being advanced. One of the main points of criticism is that education for development is a new form of imperialism and Western hegemony that advances neoliberal agendas (Tarabini, 2010; Breidlid, 2016; Regmi, 2016; McDuie-Ra and Rees, 2010).

Around the turn of the millennium, a new collaboration in development between secular and faith based organizations (FBOs) emerged. Again, the World Bank acted as a leader by convening the interfaith organization World Faith Development Dialogue in 1998 (Stambach, 2005). It has since become clear that development cannot ignore spirituality and religion for various reasons. The most important one is that religion plays a crucial role in the lives of most of the beneficiaries of development initiatives. "Religion and development are not separate spheres of life - they are intertwined and each influences the other" (Rakodi, 2012: 635). The separation of the sacred and the secular must therefore be seen as a Western exception rather than the norm. The prognosis that secularization would make religion obsolete has not come true and some speak of a recent resurgence of the spiritual (Deneulin and Rakodi, 2011). However, the collaboration between secular and faith-based development initiatives has not been an 
easy journey and much of the original enthusiasm has faded (Haynes, 2013). This is largely due to the different worldviews between the secular and the faith-based institutions, a gap that neither side was totally committed to overcome (Stambach, 2005; Tyndale, 2000). Nonetheless, FBOs have consolidated their role as important players in international development.

Research on FBOs was almost inexistent merely 20 years ago, but has grown considerably since the new millennium (for recent reviews of the literature, see Clarke and Ware, 2015; Deneulin and Rakodi, 2011; Heist and Cnaan, 2016; Tomalin, 2012). Two major insights have emerged from the literature: a) FBOs are very diverse and must be seen on an individual basis. Generalizations are fraught with difficulty. b) The impact of FBOs on development is ambiguous and there are some clear tensions. There seem to be some advantages in comparison to secular organizations. James (2011) identifies the following: efficiency, reaching the poorest at the grassroots; a long-term, sustainable presence; being valued by the poorest; providing an alternative to a secular theory of development; eliciting motivated and voluntary service; encouraging civil-society advocacy; providing spiritual teaching, hope, meaning and purpose (111). However, these advantages are not uncontested (Tomalin, 2012). James (2011) also cautions that FBOs must be "handled with care" (109) for next to their added value, there are also some major concerns. These include, amongst others, proselytizing (Bradley, 2005), gender issues (Tadros, 2010; Tomalin, 2007), and importing of faith-based values and models (Lunn, 2009).

The difficulty of making general claims about FBOs has led to the call for "a more context-sensitive and case-by-case approach" (Tomalin, 2012: 690) to researching FBOs, "requiring a shift from positivist to interpretivist research methods" (Deneulin and Rakodi, 2011: 45) and

the need for hermeneutic, interpretive studies of inter- subjective meanings, arguing that 'development research on religion is . . not only about collecting "data" that are subject to verification and technical manipulation, but also first and foremost about studying the meanings that people give to their social 
practices and religious adherence'. (Jones and Peterson, 2011: 1296)

This article describes a case study of one particular Christian FBO called Servants to Asia's Urban Poor (Servants). The goal of the study was to investigate the tensions described above from the perspective of the Servants staff. The main research question was: When and to what degree do the FBO staff experience their Western identity and their Christian faith as positive, negative or ambivalent factors in their work as educators in development? Semi-structured interviews were used to explored the lived experience of four Servants workers. The results show a nuanced picture of tensions within faithbased staff workers. Based on the research literature that describes how different FBOs have different stances on issues such as Western hegemony, evangelism, gender, etc., the main claim of this article is that these topics also create tensions within the individual experience of each faith-based worker. Categorizing FBOs and making claims about their stances can only take us so far. It needs to be acknowledged that the individual reality of each worker is more complex and multi-faceted, and that he or she does not just subscribe to a fixed set of beliefs, but that they remain fluid and adaptable to context.

The next section of this article will introduce existing typologies of FBOs, a description of the Servants to Asia's Urban Poor, and definitions for spirituality, faith and religion. Section three of the article will describe the method used for the study. Section four presents the results and the discussion thereof. The final section offers conclusions, suggestions for further research and recommendations for practical application of the research findings.

\section{Faith-Based Organizations}

The field of FBOs is complex and diverse. Even when focusing only on Christian FBOs, there are major differences between the various actors. There is no clear definition of what an FBO is (Sider and Unruh, 2004). In order to create an overview of the sector, a number of typologies of FBOs have emerged recently that categorize FBOs according to their function and to the extent to which faith is expressed in their activities. Clarke 
(2008) suggests five types of FBOs in the development context: representative organisations, charitable or development organisations, socio- political organisations, missionary organisations and radical, illegal, or terrorist organisations. He further proposes a typology for the role of faith within the organization: passive, active, persuasive or exclusive. This is similar to Sider and Unruh's (2004) continuum of the degree to which faith is present in the various aspects of the organization: faithpermeated, faith-centered, faith-affiliated, faith background, faith-secular partnership, and secular.

\section{Servants to Asia's Urban Poor}

This study focuses on one particular Christian FBOs called "Servants to Asia's Urban Poor" (Servants). Servants is a small international ecumenical FBO that works in small teams of expats (five to ten members) predominantly in slum areas in South-East Asia (India, Indonesia, Burma, Philippines, Cambodia). Servants has sending offices in the US, Canada, UK, Australia, New Zealand and Switzerland. It fits in most closely with Clark's (2008) charitable or development organization and active faith type, meaning that while faith is at the organizations' core, the practical focus of the projects is on community development rather than on religious life. Within Sider and Unruh's (2004) continuum, Servants would fit with the faith-centered type, meaning that faith and theology play a central role in the organization's central principles and policies. The organization's vision and mission statements as well as development strategies and staff training requirements can be found at www.servantsasia.org. Servants does not exclusively focus on educational programs, but most projects have an educational component.

Servants is part of the "New Friars" network (together with Word Made Flesh, Urban Neighbours of Hope, Servant Partners and InnerCHANGE). The New Friars organizations published a shared framework of values that encapsulates their vision and mission (Bessenecker, 2010). The New Friars organizations are: a) Incarnational: staff are living in the urban poor communities where the projects take place. b) Missional: working for holistic community transformation and "shalom...[the] idea of prosperity, 
justice, well-being and completeness" (Engdahl and Krieg, 2010: 61). c) Marginal:

questioning the dominant culture's social, economic and political agendas. d) Devotional: integrating spiritual practices (prayer, contemplation etc.) into everyday life. e) Communal: staff living in close proximity to one another.

\section{Definition of Faith, Spirituality and Religion}

It is important to define what is meant by the terms faith, spirituality and religion in this study because there are no agreed-upon definitions for these terms. Some define spirituality very broadly as a universal human experience and a personal quest of meaning-making and connecting with the sacred or transcendent (Peres et al., 2007) They see it distinct from religiosity, which can be defined as a set of beliefs endorsed by a religious group or institution (de Jager Meezenbroek et al., 2012). However, in the context of the FBO, it becomes clear that it does not make sense to separate the two concepts because they overlap to a great degree. I therefore use faith as a holistic term that encompasses both the spirituality and the religiousness of the participants, agreeing with Zinnbauer \& Pargament (2014) that "religiousness and spirituality are multilevel constructs - that is, they are related to biological, affective, cognitive, moral, relational, personality or self-identity, social, cultural, and global phenomena." (29) This study is particularly interested in the phenomenological construct of significance of the participants' faith in the development setting.

Significance... refers to a particular set of valued, meaningful, or ultimate concerns. These concerns may be psychological (e.g., growth, self- esteem, comfort), social (e.g., intimacy, social justice), physical (e.g., health, fitness), material (e.g., money, food, cars), or related to the divine (e.g., closeness with God, religious experience). (Zinnbauer and Pargament, 2014: 33).

\section{Method}


This research was conducted using semi-structured interviews in a case study design. The interviews were analyzed according to the principles of Interpretative Phenomenological Analysis (IPA, Smith, Flowers and Larkin, 2009), a qualitative method with an idiographic focus (Pietkiewicz and Smith, 2014), IPA's foundation is a constructionist epistemology. It assumes that meaning making happens through a double hermeneutic in which the researcher co-creates meaning by interpreting the participants' interpretation of their experience (Smith and Osborn, 2003). It is interpretative in a sense that it implies there are no objective truths, but that "truth" or meaning is created by the individual within his or her social relationships (Willig, 2001).

\section{Researcher}

As a researcher, I have been working with New Friars organizations for several years. While I have not personally worked in education for development in the Majority World, I have supported staff workers in such programs in a support capacity which has offered me insight into some of their joys and struggles of working in the field.

\section{Participants}

IPA necessitates purposive sampling. The participants are all Caucasian Western Christian FBO staff in their thirties. They work in a leadership position in communitybased educational programs in an urban poor context in Asia. They all hold degrees from western universities. They were approached by email through the researcher's professional network and invited to participate in the study. All names are pseudonyms.

1) Alan, US American, 30 years old, director of a literacy program for the urban poor in India.

2) Rita, Australian, 38 years old, director of a preschool program for urban poor children in Cambodia.

3) Dan, US American, 32 years old, director of an educational program for urban poor children in India.

4) Gabi, US American, 31 years old, director of a preschool program for urban poor children in Indonesia. 


\section{Data collection}

A semi-structured interview of 60 to 90 minutes was conducted with each participant in person (Alan) or via Skype (Rita, Dan, Gabi). Open-ended questions focusing on their experience as a) Westerners and b) Christians in a non-Western nonChristian context were asked. The interviews had a good flow to them and the participants were willing to share openly and vulnerably. All interviews were recorded and transcribed verbatim.

\section{Data analysis}

The transcripts were analyzed according to IPA guidelines (Smith et al., 2009). I read and re-read the transcripts in order to immerse myself into the participants experiences, taking notes on initial observations. I then coded each transcript in detail. The next step entailed identifying emergent themes in each transcript and then grouping them into superordinate themes. In a last step, I identified the most prominent superordinate themes that were present in each account. I found four prominent themes that will be presented in the next section.

\section{Results}

Through the analysis of the transcripts, four major themes that were present in each account could be identified. They all encompass an area of tensions that the participants experienced in their role as a Western Christian educator in a non-Western non-Christian context. They are: a) cultural tensions, b) tensions of being a Christian, c) tensions of sharing the faith, and d) tensions around gender equality. The sections below elaborate on these tensions and illustrate them by providing selected verbatim extracts from the participants' accounts.

\section{Cultural Tensions}

One of the main criticisms that has been brought forward against Western-led education for development is that Western values and neoliberal paradigms are imported by NGOs and may harm the beneficiaries (i.e. Tarabini, 2010). This tension between wanting to help by bringing educational know-how and seeing the danger of implementing Western ideas that may or may not be appropriate, was very present in the participants' accounts. 
I think what I offered maybe was a fresh perspective or an outside kind of critical thinking mind who could imagine a different way and help paint a picture or ask questions... [but] I had to be careful not to jump to conclusions or to think I had all the answers or to have a savior complex probably. So our confidence and time and wealth and critical thinking, stuff that my Western background really pushed on me, that could be used to dominate or to be helpful I guess...I wanted to not just tell them what I could do for them, but ask them what they wanted. Even though I didn't agree with all their practice, I wanted to come alongside them because they were the local people doing stuff. (Dan)

It is interesting to note that all participants stressed the fact that living amongst the beneficiaries, learning from them, becoming friends and working with instead of for them was an integral part of their work. They all spent the initial year of their assignment just living in a slum community and learning language and culture. It's a beautiful culture that I can learn so much from. I'm trying to be as culturally sensitive and Indonesian as possible. We are trying to be as contextual as we can. (Gabi)

And yet despite the stance of learning from the local culture, a negative view of the local school system was prevalent amongst the participants: The public schools are really really terrible. The pedagogy in India is, in my perspective, quite primitive. Like it's rote memorization, and when kids make mistakes, it's very frequent that they get hit for making a mistake (Alan). Also, the indigenous cultural view of the poor or marginalized as of little value was questioned: I mean, this is a Western perspective of that, so it's not a particularly good or favorable critique, but the [Cambodian system of education] is not really working well...If you are poor, you are not worth a lot (Rita).

This was to be met with a quite clear educational agenda that was informed by the participants' Western educational background. The educational programs that the FBOs offered were to be more creative, play-based, fun, less authoritarian, have fewer children per classroom, and were to foster critical thinking, self-expression and good relationships between teachers and students. They were to be more inclusive of poor and marginalized (i.e. disabled) students. The participants' accounts make it clear that there was a real 
tension between critiquing and trying to improve what they regarded as dysfunctional school systems that disempower children and being culturally sensitive and not wanting to superimpose Western values.

I wanna be careful with what I say for other people....There are a million different ways of how to teach, how to learn and to celebrate different subjects. But I do believe that a lot of the injustice and poverty and cycles of pain and suffering that I see can certainly benefit from some more critical thinking. Not only could that produce creative solutions in poverty contexts, but I think that could help people realize within themselves that they have something beautiful to offer. (Dan)

It seems that all participants struggled towards finding a balance between wanting to change or improve the system while at the same time keeping a posture of being a learner and needing to submit to a certain degree to culturally appropriate ways of doing education. One way the participants worked out this tension was by employing predominantly local teaching staff and having more of an empowering and advisory role. In their eyes, this would maintain some of the culturally appropriate interaction in the classroom.

\section{Tensions of being Christian}

A further tension that could be identified in the participants' accounts was that of being a Christian in a non-Christian context. It becomes clear that the four participants see both clear advantages and disadvantages of being faith-based.

One of the main advantages of faith was seen in the way it provides a common ground for connecting with other people of faith, even if they do not share the same faith.

I think it would be really hard for people who didn't have faith, like atheists, to interact with our neighbors because our neighbors are people of faith. A different faith, but they can respect that we have a different religion. But they wouldn't understand at all if someone didn't believe in God, that would be completely out of their realm of reality. (Gabi)

Faith was further referred to as a source of hope and vision. It provided the participants with a holistic lens through which they were able to see poor and marginalized people as 
beloved children of God who were as valuable as anyone else, and to work towards “human flourishing” (Alan).

I come from a Western culture, with a Christian faith, which sees all people as valuable and all people having value inherently, whether they have disabilities or they are young children or whatever, that's very different to Cambodian culture. (Rita)

It gave them the motivation to move into and work with a slum community in the first place and the resilience to not leave when things got hard.

Because I believed that being a serious follower of Jesus meant living in communion and connection with people on the margins and to do it in an incarnational way of living with them. So I moved to India but also to a slum community to be with the people as friends and to learn from the people. (Dan)

On the other hand, the participants were also aware of clear disadvantages of working for a Christian FBO, which may include negative perception, harmful theology, a Westernized expression of Christianity, and power issues.

We didn't automatically want to be put into the Christian category which comes with a whole set of baggage around colonialism and power and prestige and antagonism at times. (Alan)

Christianity is a whole different culture and world and associated with a lot of Western things that aren't even from the Bible, so how to make that culturally appropriate, and that it's still transformational for people? (Gabi)

Dan summed up this tension:

I think that Christian development has the opportunity to be very, very bad for the world, but also the best kind of development, depending on the theology. So I can't judge a faith-based organization on the fact that they are faith-based. I want to look at what their core values are and if it's a place of true empowerment and healing and freedom and participation, peace-making and equality, and reconciliation here and now. 


\section{Tensions of sharing one's faith}

Another major issue identified by the literature on FBOs is that of proselytizing (Bradley, 2005). Both Clark (2008) and Sider and Unruh (2004) show that there is a spectrum of how actively FBOs engage in evangelism. However, the accounts of the participants of this study demonstrate that there are tensions regarding sharing one's faith within each organization and even within each individual faith-based worker. On the one hand, there is the desire to share with others the hope, freedom, meaning, values and love the participants' faith provides for themselves.

I am convinced that the way of Jesus is completely inclusive and completely peaceful...And I think even how it impacts my desire to listen to the voices of the kids or the elderly or the women or the people with disabilities or people in vulnerable areas, that's something I learned from Jesus....So in that sense, I would love for people to see some of the things I talk about in Jesus. (Dan)

On the other hand, all participants voice that they are uncomfortable with the term evangelism and that they rather share too little than too much about their faith.

We use more an approach of "if people ask us questions", we 'll be more open and conversing with them, and sharing Jesus through acts of love like providing a free school...(Gabi).

I'm not shoving Jesus down anyone's throat (Rita)

I think we were careful to communicate that this was our worldview and that because of that we wanted to engage with them, but also that our purpose wasn't to get them to become like us. (Alan)

So these kids are in the slum and they are dealing with a lot of things and then they are told that this Christian god is going to send them to hell if they don't believe in that god. And that's honestly what most Christians in the world believe I think....but it sounds like child abuse and toxic evangelism to scare poor kids into converting. So my group, we had our gentle way of social justice, the good 
news of God's peace and that we don't need to be afraid, that God is love and God is with us and that we can share this love out of a place of being loved. (Dan)

An additional issue that came up for the participants in regard to evangelism was that they at times felt donor pressure to be more proactive in their evangelism. Alan recounts how they lost financial support and experienced "significant push-back" because their work was “insignificant if souls weren't also being saved”. Dan said that some supporters seemed to have this attitude of "ultimately, gotta save them from God's angry angry abusive wrath".

\section{Tensions around gender equality}

A further major issue identified by research on FBOs is that of gender inequality. FBOs are often accused of hindering efforts towards gender equality by importing a very conservative gender agenda (Tomalin, 2007). It is interesting to see in the participants' accounts that they all pursue an active agenda to promote gender equality in their educational programs. Dan has developed curriculum to promote gender equality in Indian primary school education. Alan has organized workshops on gender equality.

I would say talking about gender was one of the things that we pushed probably the hardest on in terms of questioning the status quo in families and in our community. So pushing for families to prioritize the education of their daughters, pushing for families to delay the marriages of their daughters, pushing for equality of treatment between their kids, pushing for women to be allowed to work. (Alan)

Rita works towards greater gender sensibility in teacher education and Gabi models gender equality by employing her husband as a preschool teacher (instead of a woman). They also try to model different gender roles in their marriage for the community to see. However, there is a keen awareness that the Christian faith community's role in promoting gender equality has oftentimes been unhelpful.

In our organization, the gender expectation was for things to be very egalitarian. I would say much more so than even American culture is...[but] I think in many ways, the church is behind Western culture in terms of gender equality. (Alan) 
So in some contexts I would prefer a Muslim to be doing the work, not a

Christian, because I believe that some Christians can promote gender inequality and promote violence and promote fear. So if a Muslim or a Hindu can do their work without promoting those things and a Christian would, I would rather them do it. (Dan)

The participants thus distance themselves from certain aspects of the Christian faith community while at the same time being aware that they are part of it.

\section{Discussion}

\section{Cultural tensions}

Both education for development initiatives and faith-based development initiatives have been criticized for promoting Western hegemony (Tarabini, 2010). At the same time, as expressed by the participants, faith and religion have the potential to offer an alternative, more holistic discourse for development, as in education the concept of human flourishing as opposed to human capital (Tadros, 2011). Also, at various times in history, the Christian faith functioned as a counter-hegemonic force of liberation, as "the theme of justice for the poor, the marginalized and the alien is central to the Hebrew scriptures" (Ferris, 2005: 311). Examples of these can be found in such movements as liberation theology (Smith, 1991), black theology (Simms, 2000) or in contemporary faith-based resistance movements (i.e. Occhipinti, 2015). Western FBOs that work in education for development are therefore seemingly caught in a tension. On the one hand, in the World Bank's terms, a partnership is needed for "bridging the gulf...separating [secular] development and faith institutions" (Stambach, 2005: 210). This partnership would basically mean the partnering FBO would need to adopt secular institutions' educational strategy and implement a Western approach to development. On the other hand, as we have seen in the results section, FBOs and their staff often have their own, theologically based, vision for development, like moving into a slum in solidarity with the poor and in order to build relationships. The staff in this study are highly sensitive to cultural circumstances and their role in possibly importing inappropriate Western values. Instead of blindly believing in neoliberal development approaches, they struggle to figure 
out what good and holistic development looks like in their local context. In that sense, a general critique that Western Christian-based NGOs automatically negatively impact local communities by importing neoliberal values must be refuted. More credit needs to be given to the single FBO staff who may be well aware of the dangers of Western hegemony and who may approach this issue with great diligence.

\section{Tensions of being Christian}

The research community that explores FBOs seems divided to a certain degree with voices who advocate for the benefits of faith in development and those who caution against it. It has been acknowledged that FBOs are very diverse (Lynch and Schwarz, 2016). As shown above, attempts have been made to come up with typologies to create a better overview of the different types of FBOs and their different agendas (i.e. Clarke, 2008). However, it has not been until very recently (i.e. Lynch and Schwarz, 2016) that there has been a greater focus on the diversity within each FBO. Such diversity is especially true for ecumenical FBOs that define their vision and mission through orthopraxis rather than orthodoxy. For example, it is not uncommon to have on the same Servants field team a Catholic, an Anglican, and a Mennonite team member. Each one of them will most likely experience their faith identity quite differently. What becomes apparent however is that faith identity is seen by the staff themselves as both beneficial and problematic. So instead of saying "faith is good for development" or "faith is bad for development", what we can learn from the practitioners is that there is no black and white scenario, but that faith identity is experienced as somewhat paradoxical and that this identity is constantly being re-negotiated within the context the practitioner finds him- or herself.

What also becomes clear from the participants' accounts is that faith can offer an alternative, more holistic approach to development in general and to education for development in particular. This is in line with Tadros' (2011) observation that

human flourishing is one alternative reimagining of development, put forward by some faith-based organisations, which seeks to shed light on the limitations of 
existing mainstream development paradigms that fail to take into account relational dimensions of wellbeing and its non-material aspects. (63)

We can say that in this way, faith-based development is very much in line with secular holistic approaches to development, such as Sen's (1985) and Nussbaum's (2011) capability approach that focus on human capacity rather than human capital, or Hill's (2003) empowerment approach. Again, it is important here not to generalize and conclude that faith automatically creates more holistic development. While the positive seems to predominate amongst our participants, they also acknowledge the cultural baggage that is attached to Christianity.

\section{Tensions of sharing the faith}

Proselytism is seen as the Achilles heel of faith-based development (Bickley, 2015). However, as Lynch and Schwarz (2016) point out, commentators and scholars often treat proselytism with too broad a brush, coloring religious groups automatically with suspicion instead of interrogating the meaning of religious mandates for the groups concerned. But Christian groups are far from united on whether or not to promote conversion. Instead, they debate within and among themselves the meaning and legitimacy of religious and cultural mandates regarding pluralism, evangelism, "witness," and proselytism in aid work. (2)

The participants' accounts show clearly that none of them had an agenda to convert people to Christianity, despite an inherent desire to share the faith that they experience as a source of hope, love and motivation. In this context, Lynch and Schwarz (2016) make the interesting observation that proselytism is not just an issue for FBOs, but (if defined more generally as trying to promote a specific ideology over an existing one) an issue for development actors in general:

Analysts should examine the propensity of humanitarian and development groups to spread the faith of neoliberal forms of aid provision as well as faiths based in religious traditions. (4) 
Again, it is important here to analyze not only FBOs case by case, which would still be using "too broad a brush", but to interrogate the individual worker and thus paint a nuanced picture. This is not to say that there are not very harmful examples of Christian organizations doing evangelism in non-Christian contexts. But it is to say that the faithbased educator may have reflected much more on this issue and may work more contextsensitive than a general classification would acknowledge. This is in line with James' (2009) finding that there is an increased reticence among development workers to articulate their faith because of the awareness of negative examples of FBOs or churches in this area.

\section{Tensions around gender equality}

Gender is a key issue in education for development. Goal 2 of the Millennium Development Goals, to achieve universal primary education, is closely tied to goal 3, the promotion of gender equality and empowerment of women. Gender is also clearly a sensitive topic in FBOs. It is important to understand that FBOs are highly diverse, and that while some work for the promotion of gender equality, some could "jeopardize hardwon commitments to gender equality" (Pearson and Tomalin, 2008: 65), and some may paradoxically do both at the same time. (Connor, 2011; Walker, 2011). Tadros (2010) outlines four gender conundrums for FBOs: 1) It is difficult to determine an FBO's gender agenda because they often have different standpoints on different gender issues, 2) FBOs empower women while at the same time prescribing gender roles, 3) FBOs might be effective on a grassroots level, but are at the same time importing non-local values, 4) FBOs may deliver services on conditions that beneficiaries adopt their gender roles. While these classifications and conundrums may be helpful in a general sense, they ignore how the individual staff member wrestles with the tension of his and her Christian heritage and the desire to work for gender equality. The results of this study show a great awareness of the participants towards gender issues in their own culture, in their faith tradition and in the host culture also. They seem to have put considerable effort into reflecting on their own gender ideology and have shown ways of working for greater 
gender equality. Again, what stands out here is how they interpret their own doctrines on gender, and they seem to be integrating some Christian feminist theological thought.

\section{Conclusions}

In general, it can be concluded that the picture of FBOs presented by the literature is not differentiated enough. While the field is generally divided into those who see the participation of FBOs in education for development in a positive light and those who generally have a critical perspective, what is largely ignored is the fact that many FBO staff members wrestle with great tensions. Their reality is much more of a "both / and" reality than an "either / or" reality. They need to live within the paradoxes that are inherent in their Christian faith and Christian doctrine. Deneulin and Rakodi's (2011) observation that "polarized debates between critics and advocates of religion are unhelpful and insufficient" (52) seems to fit well with this study. The individual experiences come across as more nuanced, reflected and perhaps wise than what is portrayed in much of the research literature. I therefore agree with Offutt, Probasco and Vaidyanathan's (2016) statement that “arguments about whether religion is inherently good or bad for particular development outcomes such as economic growth are ultimately futile" (2) and that many studies lead to contradictory claims. I would add to their conclusion that the contradictory claims are perhaps not only due to research design, but exist because there are inherent paradoxes and tensions in the Christian faith and its application to development.

In that sense, it becomes almost impossible to make general claims about the benefits or pitfalls of faith in development but possible to make personal claims based on workers' individual worldview, theology and experience. The individual faith-based workers need to be given more credit for having done their personal inner work of reflecting on their faith doctrines and traditions and how these impact the context in which they work.

A general recommendation for FBO policy makers, trainers and member care personnel would be to make these tensions explicit already in the pre-field staff training phase. Each organization could implement training modules that raise awareness among 
prospective staff about personal tensions that might arise in the area of culture, evangelism and gender. This would offer room for discussion and would further increase awareness of the complexity of working in faith-based organizations and programs. Such intentional reflection could then perhaps help facilitate the dialogue with secular development actors, potentially leading to less polarized views on faith-based development.

\section{Limitations}

This study has clear limitations. First and foremost, it only focused on one FBO. Being an ecumenical FBO, Servants is also not a typical FBO. The results can not therefore be generalized for all FBOs. A further limitation is the small sample size. While this allows for depth and for ample use of personal quotes in academic writing and thus helps the reader to "hear" each participant, it again limits the generalizability of the study. A final limitation comes from the purposive sampling. In order to be able to compare similar experiences, this study only worked with relatively young Caucasian staff. Further qualitative research with Christian FBO staff from different organizations, with different ethnic backgrounds or from a different age bracket could be helpful to corroborate the findings of this study. 


\section{References}

Bessenecker SA (ed.) (2010) Living Mission: The Vision and Voices of New Friars. Downers Grove: InterVarsity Press.

Bickley P (2015) Problem of Proselytism. London: Theos.

Bradley T (2005) Does compassion bring results? A critical perspective on faith and development. Culture and Religion 6(3): 337-351.

Breidlid A (2016) The global architecture of education and its ramifications for education and learning in the Global South. In: Cole DR and Woodrow C (eds.) Super Dimensions in Globalisation and Education. Singapore: Springer. pp. 125-142.

Clarke G (2008) Faith-based organizations and international development: an overview. In Clarke G and Jennings M (eds.) Development, Civil Society and Faith-Based Organisations: Bridging the Sacred and the Secular. Basingstoke and New York: Palgrave Macmillan.

Clarke M and Ware VA (2015) Understanding faith-based organizations: How FBOs are contrasted with NGOs in international development literature. Progress in Development Studies 15(1): 37-48.

Connor J (2011) Development for whom? Homosexuality and faith-based development in Zimbabwe. Development in Practice 21(6): 860-869.

De Jager Meezenbroek E, Garssen B, van den Berg M, van Dierendonck D, Visser A and Schaufeli W B (2012) Measuring spirituality as a universal human experience: A review of spirituality questionnaires. Journal of Religion and Health 51: 336-354.

Deneulin S and Rakodi C (2011) Revisiting religion: Development studies thirty years on. World Development 39(1): 45-54.

Engdahl D and Krieg JL (2010) Missional: The second sign. In Bessenecker SA (ed.) Living Mission: The Vision and Voices of New Friars. Downers Grove: InterVarsity Press 
Haynes J (2013) Faith-based organisations, development and the World Bank. In: Carbonnier G, Kartas M and Silva KT (eds) International Development Policy: Religion and Development. London: Palgrave Macmillan. pp. 49-64.

Heist D and Cnaan RA (2016) Faith-based international development work: A review. Religions 7(3): 19-36.

Hill M (2003) Development as empowerment. Feminist Economics 9(2-3): 117-135.

James R (2009) What is distinctive about FBOs?. Praxis Paper 22. International NGO Training and Research Center.

James R (2011) Handle with care: engaging with faith-based organisations in development. Development in Practice 21(1): 109-117.

Jones B and Petersen MJ (2011) Instrumental, narrow, normative? Reviewing recent work on religion and development. Third World Quarterly 32(7): 1291-1306.

Lunn J (2009) The role of religion, spirituality and faith in development: A critical theory approach. Third World Quarterly 30(5): 937-951.

McDuie-Ra D and Rees JA (2010) Religious actors, civil society and the development agenda: The dynamics of inclusion and exclusion. Journal of International Development 22: $20-36$.

Narayan D, Chambers R, Shah M K and Petesch P (2000) Voices of the Poor: Crying out for Change. New York: Oxford University Press.

Nussbaum M (2011) Creating Capabilities: The Human Development Approach. Cambridge: Harvard University Press.

Occhipinti L (2015) Faith based organizations and the neoliberal state: Creating resistance in Northern Argentina. Journal of International and Global Studies 7(1): 2-15.

Offutt S, Probasco L and Vaidyanathan B (2016) Religion, poverty, and development. Journal for the Scientific Study of Religion 55(2): 207-215. 
Pearson R and Tomalin E (2008) Intelligent design?: A gender-sensitive interrogation of religion and development. In Jennings M and Clarke G (eds) Development, Civil Society and Faith-Based Organisations: Bridging the Sacred and the Secular. New York: Palgrave Macmillan.

Peres JFP, Moreira-Almeida A, Nasello AG and Koenig HG (2007) Spirituality and resilience in trauma victims. Journal of Religion and Health 46(3): 343-350.

Pietkiewicz I and Smith JA (2014) A practical guide to using Interpretative Phenomenological Analysis in qualitative research psychology. Psychological Journal 20(1): 7-14.

Rakodi C (2012) A framework for analysing the links between religion and development. Development in Practice 22(5-6): 634-650.

Regmi KD (2016) Critiquing hegemony of capitalism: A call for popular education. International Critical Thought 6(2): 190-208.

Sider RJ and Unruh HR (2004) Typology of religious characteristics of social service and educational organizations and programs. Nonprofit and Voluntary Sector Quarterly 33(1): 109-134.

Smith C (1991) The Emergence of Liberation Theology: Radical Religion and Social Movement Theory. Chicago: University of Chicago Press.

Smith JA, Flowers P and Larkin M (2009) Interpretative Phenomenological Analysis: Theory, Method and Research. London: Sage.

Smith JA and Osborn M (2003) Interpretive phenomenological analysis. In: Smith JA (ed.) Qualitative Psychology: A Practical Guide to Research Methods. London: Sage. pp. 51-80. 
Stambach A (2005) Rallying the armies or bridging the gulf: Questioning the significance of faith-based educational initiatives in a global age. Indiana Journal of Global Legal Studies 12(1): 205-226.

Sen A (1985) Commodities and Capabilities. Oxford: Elsevier Science Publishers.

Tadros M (2011) The faith factor in reimagining development. IDS Bulletin 42(5): 63-67.

Tarabini A (2010) Education and poverty in the global development agenda: Emergence, evolution and consolidation. International Journal of Educational Development 30(2): 204-212.

Tomalin E (2007) Gender Studies Approaches to the Relationships between Religion and Development (Religions and Development Research Programme Working Paper No. 08) Birmingham: University of Birmingham, International Development Department.

Tomalin E (2012) Thinking about faith-based organisations in development: where have we got to and what next?. Development in Practice 22(5-6): 689-703.

Tadros M (2010) Faith-Based Organizations and Service Delivery: Some Gender Conundrums. Geneva: United Nations Research Institute for Social Development.

Tyndale W (2000) Faith and economics in 'development': a bridge across the chasm? Development in Practice 10(1): 9-18.

Walker B (2011) Christianity, development, and women's liberation. In: Tomalin E (ed.) Gender, Faith and Development. Oxford: Oxfam. pp. 65-74.

Willig C (2001) Introducing Qualitative Research in Psychology: Adventures in Theory and Method. Buckingham: Open University Press.

World Bank (2011) Learning for all: Investing in people's knowledge and skills to promote development. World Bank Group Education Strategy 2020. Washington, DC: World Bank. 
Zinnbauer BJ and Pargament KI (2005) Religiousness and spirituality. In: Paloutzian RF and Park CL (eds.) Handbook of the Psychology of Religion and Spirituality. New York: The Guilford Press. pp. 14-44. 